ARTICLE

Received 23 Sep 2014 | Accepted 1 Dec 2014 | Published 14 Jan 2015

DOI: $10.1038 /$ ncomms7013

OPEN

\title{
A molecular nematic liquid crystalline material for high-performance organic photovoltaics
}

Kuan Sun ${ }^{1,2,3, \star}$, Zeyun Xiao ${ }^{1, \star}$, Shirong Lu ${ }^{1, \star}$, Wojciech Zajaczkowski ${ }^{4}$, Wojciech Pisula ${ }^{4}$, Eric Hanssen ${ }^{5}$, Jonathan M. White ${ }^{1}$, Rachel M. Williamson ${ }^{6}$, Jegadesan Subbiah', Jianyong Ouyang ${ }^{2}$, Andrew B. Holmes ${ }^{1}$, Wallace W.H. Wong ${ }^{1} \&$ David J. Jones ${ }^{1}$

Solution-processed organic photovoltaic cells (OPVs) hold great promise to enable roll-to-roll printing of environmentally friendly, mechanically flexible and cost-effective photovoltaic devices. Nevertheless, many high-performing systems show best power conversion efficiencies (PCEs) with a thin active layer (thickness is $\sim 100 \mathrm{~nm}$ ) that is difficult to translate to roll-to-roll processing with high reproducibility. Here we report a new molecular donor, benzodithiophene terthiophene rhodanine (BTR), which exhibits good processability, nematic liquid crystalline behaviour and excellent optoelectronic properties. A maximum PCE of 9.3\% is achieved under AM $1.5 \mathrm{G}$ solar irradiation, with fill factor reaching $77 \%$, rarely achieved in solution-processed OPVs. Particularly promising is the fact that BTR-based devices with active layer thicknesses up to $400 \mathrm{~nm}$ can still afford high fill factor of $\sim 70 \%$ and high PCE of $\sim 8 \%$. Together, the results suggest, with better device architectures for longer device lifetime, BTR is an ideal candidate for mass production of OPVs.

\footnotetext{
${ }^{1}$ School of Chemistry, Bio21 Institute, The University of Melbourne, 30 Flemington Road, Parkville, Victoria 3010, Australia. ${ }^{2}$ Department of Materials Science and Engineering, National University of Singapore, 7 Engineering Drive 1, Singapore 117574, Singapore. ${ }^{3}$ Department of Renewable Energy, School of Power Engineering, Chongqing University, 174 Shazhengjie, Shapingba, Chongqing 400044, China. ${ }^{4}$ Max Planck Institute for Polymer Research, Ackermannweg 10, 55128 Mainz, Germany. ${ }^{5}$ Advanced Microscopy Facility, Bio21 Institute, The University of Melbourne, 30 Flemington Road, Parkville, Victoria 3010, Australia. ${ }^{6}$ MX Beamlines, Australian Synchrotron, 800 Blackburn Road, Clayton, Victoria 3168, Australia. ${ }^{\star}$ These authors contributed equally to this work. Correspondence and requests for materials should be addressed to J.O. (email: mseoj@nus.edu.sg) or to W.W.H.W. (email: wwhwong@unimelb.edu.au) or to D.J.J. (email: djjones@unimelb.edu.au).
} 
$\mathrm{D}$ espite recent developments in solid-state photovoltaic devices $^{1-3}$, bulk-heterojunction (BHJ) organic photovoltaics $(\mathrm{OPVs})^{4}$ continue to be a promising low-cost renewable energy technology. The reasons for this outlook include the versatility of organic semiconducting materials and simple device architectures that can be constructed from a variety of printing techniques. The development of the BHJ OPVs has been rapid in recent years driven by a combination of organic material design, interface engineering and improvements in device geometry. The reported power conversion efficiency (PCE) of single-junction small-area devices is now routinely in the $6-8 \%$ range ${ }^{5-7}$.

Published reports of single-junction BHJ OPVs over 9\% PCE are still rare. A handful of polymeric electron donor materials and only one molecular donor have been reported in devices that reached this benchmark ${ }^{8-13}$. Molecular OPVs are an attractive alternative to polymer-based OPVs. Higher material purity can be achieved with the well-defined discrete structure of molecules and this should ensure greater reproducibility in devices ${ }^{14-16}$. To achieve high photovoltaic conversion efficiency, the material should be capable of forming good films with high molecular order. This can be achieved by smart molecular design and control over crystallization processes. For molecular semiconductors, conjugated flat and rigid backbones are preferred for easy packing via $\pi-\pi$ interactions. Good solubility is conferred through employment of the appropriate number, type and length of side chains, without hindering the packing of the backbones. The desirable donor phase in BHJ OPVs needs well-ordered nanocrystals with sizes comparable to the exciton diffusion length for efficient charge generation. Strategies simultaneously to enhance molecular order and restrict crystal size have been reported, including thermal annealing, solvent additives, solid additives and solvent vapour annealing $(\mathrm{SVA})^{7,17-22}$. Recent reports showed that the rapid SVA treatment was particularly useful in achieving high fill factor (FF) and PCE in molecular OPVs ${ }^{23,24}$. Solvent selection rules for SVA treatment were identified in our previous study ${ }^{23}$.

Despite the important progress achieved in small-area OPV devices fabricated in laboratories, the successful commercialization of OPV technology relies on the application of solutionprocessed roll-to-roll techniques for large-scale printing ${ }^{25}$. One of the challenges in printing OPV devices is in printing the optimal active layer thickness of $80-120 \mathrm{~nm}$ that many of the highperforming material systems require, while obtaining pinhole-free thin films reproducibly at high printing speed. This problem can be relieved by printing thick films with thickness over $200 \mathrm{~nm}^{26}$. Unfortunately, due to limited charge diffusion length, thick-film OPV devices often experience severe bimolecular recombination and space charge effect, leading to reduced $\mathrm{FF}$ and $\mathrm{PCE}^{27}$. So far only a few studies have achieved high photovoltaic performance on polymer-based OPVs, with active layers above $200 \mathrm{~nm}^{26,28-30}$. No report has been found for molecular OPVs.

In this work, a new molecular electron donor material, benzodithiophene terthiophene rhodanine (BTR), with a benzo[1,2-b:4,5- $\left.b^{\prime}\right]$ dithiophene (BDT) core and rhodanine peripheral units was developed and used in OPV devices giving PCEs $>9 \%$. While its $\pi$-conjugated structure is analogous to a high-performance compound reported previously $y^{7,31}$, the strategic placement of the side chains provided BTR with strong intermolecular interactions, as evidenced by its liquid crystalline (LC) behaviour. Such interactions translated successfully into excellent hole transport properties; hole mobilities up to 0.1 and $1.6 \times 10^{-3} \mathrm{~cm}^{2} \mathrm{~V}^{-1} \mathrm{~s}^{-1}$ were recorded by organic field-effect transistor (OFET) and space-charge-limited current (SCLC) methods, respectively. Thus, BTR-based OPVs with thick active layers $(300-400 \mathrm{~nm})$ could still afford PCEs of over $8 \%$ with high FF of $\sim 70 \%$. Normal cell architecture employed in this study showed a moderate device lifetime. With better cell architectures or proper encapsulation for longer device lifetime, it is believed that BTR is a very attractive candidate for roll-to-roll printed OPV modules.

\section{Results}

Physical properties of BTR. The BTR molecule was synthesized in two steps from known precursors in a good yield (Supplementary Fig. 1). The chemical structure of BTR is shown in Fig. 1a. The backbone consisting of the BDT unit, two terthiophenes and two rhodanine groups formed a coplanar structure. In comparison with analogous structures in the literature 7,31 , the side chains of BTR were shortened and positioned at the terthiophene building blocks in a regioregular manner to facilitate side-chain interdigitation ${ }^{32,33}$. In combination with the additional hexyl group on the thienylBDT unit, the side chains of BTR imparted LC behaviour (vide infra) that was not observed in previous reports.

BTR shows an excellent solubility of $211 \mathrm{mg} \mathrm{ml}^{-1}$ in chloroform, as derived from concentration and absorption data (Supplementary Fig. 2). BTR in solution displays an absorption maximum $\left(\lambda_{\max }\right)$ at $523 \mathrm{~nm}$, with an extinction coefficient $(\varepsilon)$ of $1.10 \times 10^{5} \mathrm{M}^{-1} \mathrm{~cm}^{-1}$ (Fig. 1b; Supplementary Table 1). The high $\varepsilon$ is attributed to the planarity of its backbone. The BTR solid film exhibits a red-shift of the $\lambda_{\max }$ to $572 \mathrm{~nm}$ relative to that in solution. Furthermore, an additional absorption peak at $620 \mathrm{~nm}$ appears in the absorption spectrum of a thin film. The red-shift and new absorption peak of the BTR film suggest the presence of strong intermolecular interaction and aggregation in the solid film. The absorption onset of the BTR film is at $681 \mathrm{~nm}$, equivalent to an optical frontier orbital energy gap of $1.82 \mathrm{eV}$. Determined by cyclic voltammetry (CV) (Supplementary Fig. 3), the highest occupied molecular orbital (HOMO) and lowest unoccupied molecular orbital (LUMO) of BTR are -5.34 and $-3.52 \mathrm{eV}$, respectively. The HOMO-LUMO gap of BTR is $1.82 \mathrm{eV}$, which is in good agreement with the optical energy gap. Because the open-circuit voltage $\left(V_{o c}\right)$ is largely determined by the HOMO-LUMO gap of the donor and acceptor, a deep-lying HOMO of BTR can potentially support a high $V_{\mathrm{oc}}$. In combination with fullerene acceptor [6,6]-phenyl $\mathrm{C}_{71}$ butyric acid methyl ester $\left(\mathrm{PC}_{71} \mathrm{BM}\right)$, whose LUMO level is around $-4.0 \mathrm{eV}$, the LUMO energy offset of $0.48 \mathrm{eV}$ between $\mathrm{BTR}$ and $\mathrm{PC}_{71} \mathrm{BM}$ should provide enough driving force for exciton dissociation ${ }^{34}$.

The BTR molecule has good thermal stability with a decomposition temperature of $405^{\circ} \mathrm{C}$ in nitrogen $(5 \%$ weight loss in thermogravimetric analysis, Supplementary Fig. 4). BTR exhibits a sharp differential scanning calorimetry (DSC) peak at $175^{\circ} \mathrm{C}$ (Fig. 1c), which is assigned to secondary crystalline phase transition by means of a structural analysis (vide infra). Furthermore, a melting temperature of $186^{\circ} \mathrm{C}$ into a LC phase and a clearing temperature at $196^{\circ} \mathrm{C}$ of small enthalpy into an isotropic melt were observed. Upon cooling, three exothermic peaks at 193,181 and $133^{\circ} \mathrm{C}$ were recorded. The first minor transition was attributed to the LC phase transition, while the two major ones were related to the crystallization process of the two crystalline phases. To observe directly the LC transition and precisely assign the phases, BTR powder was sandwiched in between two glass slides, heated and examined under a polarized optical microscope (POM). The BTR molecule was highly crystalline below a stage temperature of $185^{\circ} \mathrm{C}$ (Fig. 1d). Between 185 and $195^{\circ} \mathrm{C}$, the crystalline solid was replaced by a liquid crystal nematic texture (Fig. 1e). The nematic phase suggests that BTR molecules have a rigid rod-like shape, which can maintain a long-range directional order with their long axes parallelly 
a
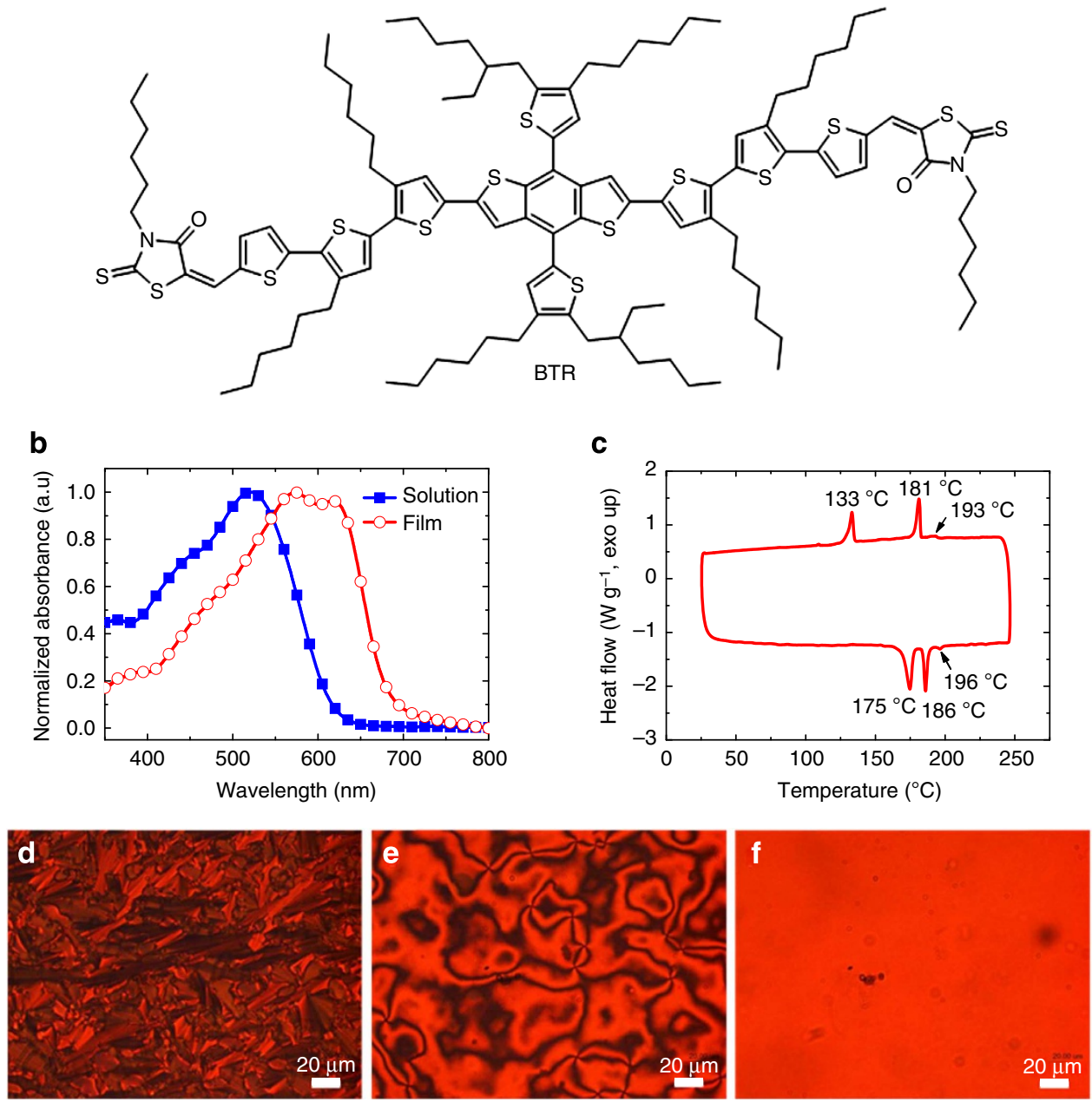

Figure 1 | BTR chemical structure and physical properties. (a) Chemical structure of BTR. (b) Normalized UV-vis absorption spectra of BTR in chloroform $\left(5 \mathrm{mg} \mathrm{ml}^{-1}\right)$ and in a spin-cast film. (c) DSC thermogram of BTR in nitrogen at a ramp rate of $10^{\circ} \mathrm{C} \mathrm{min}^{-1}$. The lower trace is from the heating cycle and upper trace from the cooling cycle. (d) BTR thin film sandwiched in between two glass slides observed under a polarized optical microscope (POM) at a stage temperature of $185^{\circ} \mathrm{C}$. (e) The POM image of the same BTR thin film at the same settings when the stage temperature rises to $195^{\circ} \mathrm{C}$. (f) The POM image taken at a stage temperature of $197^{\circ} \mathrm{C}$.

aligned. They can thus have high crystallinity in solid state ${ }^{17,35-37}$. The liquid crystal transformed above $196^{\circ} \mathrm{C}$ into an isotropic melt, leaving no prominent feature under the POM (Fig. 1f). Thereby, the small transition enthalpy determined by DSC is in agreement with the low-ordered nematic phase. The nematic LC behaviour is an important feature of the BTR molecule, implying strong intermolecular interaction resulted from side-chain modifications, and potentially high charge carrier mobility due to three-dimensional (3D) charge transport ${ }^{38}$.

Crystal packing of BTR molecules. To obtain a better understanding of the packing of BTR molecules in the solid, X-ray quality single crystals of BTR were grown from a mixed solution of 2-propanol and dichloromethane by slow evaporation. The single crystal structure was solved using data from the MX2 beamline at the Australian Synchrotron ${ }^{39}$ (Fig. 2a; Supplementary Figs 5-8). The X-ray crystal structure of the BTR molecule revealed a coplanar structure of the conjugated backbone, which should facilitate light absorption and also crystal stacking. The crystal packing is dominated by $\pi$-stacking between the individual BTR backbones that arrange themselves into $\pi$-stacked centrosymmetric dimers with an average inter-plane separation of ca $3.60 \AA$ (Fig. 2a). These individual dimers aggregate together by $\pi$-stacking, with an average interplaner separation of $3.62 \AA$ (Supplementary Fig. 6). This type of packing is consistent with the bathrochromic shifting of the absorption from solution to the solid film (J-aggregate).

The solid-state structure was also examined using twodimensional wide-angle X-ray scattering (2D-WAXS) on neat BTR filaments. The samples were prepared by filament extrusion $^{40}$, which imparted bulk orientation on the crystalline material. The 2D-WAXS pattern suggests a crystalline character of BTR in the low-temperature phase as evident by the high number of distinct reflections (Fig. 2b). The molecules are organized in a layered structure that is aligned in the direction of the fibre axis. An interlayer distance of $18.3 \AA$ is determined from reflections located in the equatorial small-angle range. On the same plane of the pattern, two $\pi$-stacking peaks appear that are related to distances of 3.70 and $3.65 \AA$ of stacked BTR dimers. These values are in the same range as found for the single crystal. Further meridional reflections are originated from intramolecular correlations along the extended conjugated BTR backbone. At $179^{\circ} \mathrm{C}$, the sample maintains a crystalline phase, however, with a slightly smaller degree of order (Supplementary Fig. 9). The interlayer spacing remains identical at $18.3 \AA$, while only one and a little larger stacking distance was observed at $3.76 \AA$. 
In a thin solid film, BTR organizes in two different molecular arrangements as indicated by the grazing incidence wide-angle X-ray scattering (GIWAXS) pattern in Fig. 2c. Reflections in the meridional plane (along $q_{\mathrm{xy}}=0 \AA^{-1}$ ) in the small- and middlerange scattering region are related to the formation of a layered structure with an interlayer distance of $18.7 \AA$. In addition, 3rdorder reflections are visible typical for a long-range order, while their position on the meridional plane of the pattern is characteristic for an edge-on molecular organization. In this

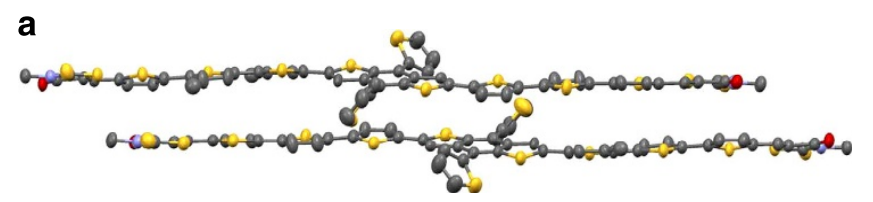

b

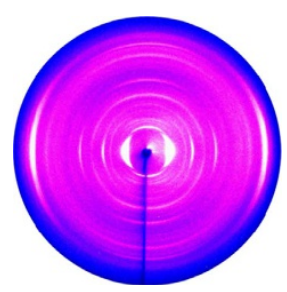

C

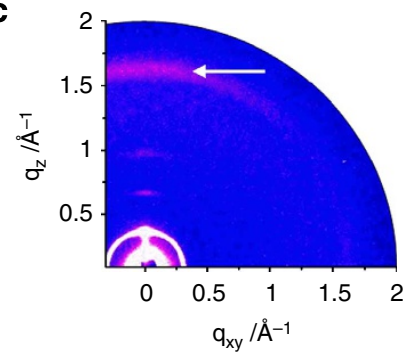

Figure 2 | Crystal packing resolved by X-ray techniques.

(a) Centrosymmetric $\pi$-stacked dimers of BTR molecules in its single crystal, the alkyl side chains have been omitted for clarity. (b) 2D-WAXS of BTR filament measured at $30^{\circ} \mathrm{C}$. (c) GIWAXS of the as-cast BTR thin film on silicon wafer via spin coating ( $\pi$-stacking reflection is indicated by an arrow). arrangement, the backbone plane is aligned perpendicular to the surface. However, the corresponding equatorial $\pi$-stacking peak of the edge-on arranged molecules assembled in the layered structure is too weak to be detected. Instead, the $\pi$-stacking reflection related to a single distance of $3.70 \AA$ is located also on the meridional plane, which is typical for a face-on arrangement. These results imply two distinct surface organizations. In the first phase, the molecules are $\pi$-stacked and face-on arranged, but do not organize in a layered structure. In the second phase, the molecules are edge-on aligned with respect to the substrate, but are disordered within the layer organization. Because charge transport in organic semiconductors is mainly via hopping between adjacent molecules, the co-existence of edge-on and faceon orientations can potentially form a $3 \mathrm{D}$ network for hopping, thus beneficial to charge transport ${ }^{41}$.

OFET mobility. To study the charge carrier transport, OFETs using different procedures were built. For top-contact devices, BTR was spin-coated from a $4.5-\mathrm{mg} \mathrm{ml}^{-1}$ toluene solutionand subsequently annealed at $179^{\circ} \mathrm{C}$. These transistors delivered hole mobilities up to $0.01 \mathrm{~cm}^{2} \mathrm{~V}^{-1} \mathrm{~s}^{-1}$ (Supplementary Fig. 10). Bottom-contact OFET devices with the BTR molecules deposited by drop-casting gave mobility values as high as $0.1 \mathrm{~cm}^{2} \mathrm{~V}^{-1} \mathrm{~s}^{-1}$ (Supplementary Fig. 11). It should be noted that the OFET devices were not intensively optimized. The primary purpose of the OFET experiments was to show the potential of the BTR material as a semiconductor.

Photovoltaic performances. The excellent solubility, strong intermolecular interaction, suitable absorption profile and energy levels, as well as encouraging semiconducting properties prompted us to explore the photovoltaic performance of the BTR a
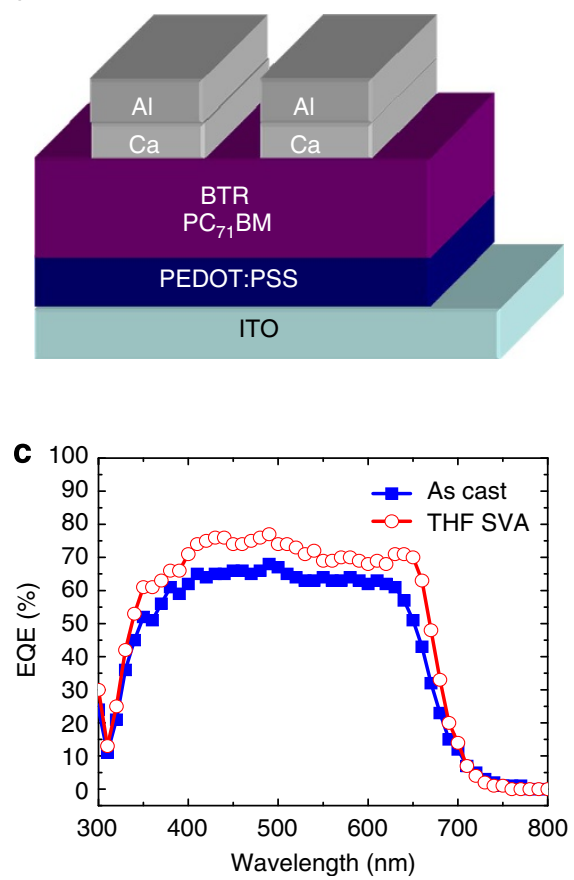

b
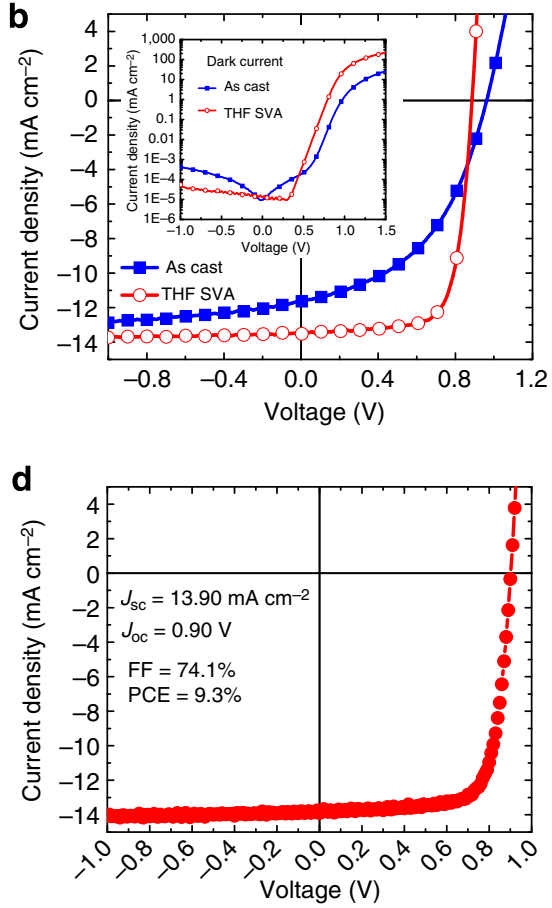

Figure 3 | Device architecture and photovoltaic performances. (a) Schematic diagram of a normal cell architecture used in this study. (b) J-V characteristics of BTR:PC ${ }_{71} B M$ BHJ solar cells with or without THF solvent vapour annealing tested in air under $98 \mathrm{~mW} \mathrm{~cm}^{-2} \mathrm{AM} 1.5 \mathrm{G}$ illumination. Inset: dark current plotted in a semi-log scale of the two solar cells. (c) EQE spectra of optimized BTR-based solar cells with or without THF SVA treatment. (d) $\mathrm{J}-\mathrm{V}$ curve of the most efficient BTR:PC ${ }_{71} \mathrm{BM}$ BHJ solar cell after $15 \mathrm{~s}$ of THF SVA measured by an independent research institute in nitrogen atmosphere under an illumination of $100 \mathrm{~mW} \mathrm{~cm}^{-2}$. 
molecule. The OPV cells adopted a simple normal architecture, with the BTR:PC ${ }_{71} \mathrm{BM}$ blend film sandwiched between a poly $(3,4-$ ethylenedioxythiophene):poly(styrenesulfonate) (PEDOT:PSS)coated indium tin oxide (ITO) transparent anode and a $\mathrm{Ca} / \mathrm{Al}$ back cathode (Fig. 3a). We further treated the active layer with SVA, which has been shown to be effective in enhancing the performance of molecular OPVs ${ }^{22-24}$. The SVA treatment was carried out by exposing the as-cast active layer to solvent vapours. According to the solvent selection rules previously identified ${ }^{23}$, tetrahydrofuran (THF) was chosen for SVA owing to the moderate solubility of BTR in THF $\left(89 \mathrm{mg} \mathrm{ml}^{-1}\right)$.

The BTR-based OPVs with an optimal active layer thickness of $250 \mathrm{~nm}$ were encapsulated and tested in air. The current density $(J)$-voltage $(V)$ curves of the best devices are shown in Fig. 3b, with the photovoltaic parameters summarized in Table 1. Without SVA treatment, the highest performance for the as-cast OPVs showed short-circuit current density $\left(J_{\text {sc }}\right)=11.64 \mathrm{~mA} \mathrm{~cm}^{-2}$, $V_{\mathrm{oc}}=0.96 \mathrm{~V}, \mathrm{FF}=47 \%$ and $\mathrm{PCE}=5.2 \%$. SVA treatment significantly enhanced the photovoltaic performance. OPVs with $15 \mathrm{~s}$ of THF SVA exhibited $J_{\mathrm{sc}}=13.52 \mathrm{~mA} \mathrm{~cm}^{-2}, V_{\mathrm{oc}}=0.89 \mathrm{~V}$, $\mathrm{FF}=73 \%$ and $\mathrm{PCE}=8.7 \%$. Device assembly was reproducible with around 60 SVA-treated OPV devices having an average PCE of $8.3 \pm 0.2 \%$. Thermal annealing was found to diminish the device performance, due to the overgrowth of the phases (Supplementary Fig. 12).

The causes for the enhanced FF after SVA treatment were investigated by measuring dark currents (inset of Fig. 3b). Compared with an as-cast molecular OPV, the SVA-treated sample displayed notably higher current density under positive bias. In great contrast, the current density was one order of magnitude smaller in reverse bias. To further understand the SVA treatment effect, series resistance $\left(R_{\mathrm{s}}\right)$ and shunt resistance $\left(R_{\mathrm{sh}}\right)$ were extracted at 1.5 and $0 \mathrm{~V}$ of the dark curves (Table 1). Without SVA treatment, the OPV had a $R_{\mathrm{s}}$ of $14.0 \Omega \mathrm{cm}^{2}$ and a $R_{\mathrm{sh}}$ of $5.5 \mathrm{M} \Omega \mathrm{cm}^{2}$. SVA treatment led to a reduction of $R_{\mathrm{s}}$ by six times and a slight increase of $R_{\mathrm{sh}}$. Together, the results suggest the SVA treatment can suppress leakage current and improve the diode behaviour.

The slight improvement in $J_{\text {sc }}$ after SVA treatment was monitored by external quantum efficiency (EQE) measurement (Fig. 3c). A high EQE of over $60 \%$ was measured in the visible region from 400 to $650 \mathrm{~nm}$ for the non-annealed OPV. The $J_{\mathrm{sc}}$ calculated by integrating the product of photon flux and EQE at each wavelength was $11.70 \mathrm{mAcm}^{-2}$, which was in good agreement with the measured $J_{\mathrm{sc}}\left(11.64 \mathrm{mAcm}^{-2}\right)$. The SVA treatment lifted the EQE in the entire absorption range. In particular, the EQE stayed above $70 \%$ between 400 and $650 \mathrm{~nm}$, and a shoulder was found at $640 \mathrm{~nm}$. As a result, the calculated $J_{\mathrm{sc}}$ increased to $13.53 \mathrm{~mA} \mathrm{~cm}^{-2}$. The EQE result clearly indicates SVA treatment plays a positive role in charge generation, transport and/or collection.

Bearing in mind that OPVs with normal cell architecture are not stable in air, we fabricated a batch of 20 devices in Singapore and 8 devices in Australia and tested them under inert atmosphere using the facilities at Solar Energy Research Institute of Singapore and the Commonwealth Scientific and Industrial Research Organisation, respectively. The best BTR-based OPV fabricated in Singapore exhibited a record efficiency of $9.3 \%$, with $J_{\mathrm{sc}}=13.90 \mathrm{~mA} \mathrm{~cm}^{-2}, V_{\mathrm{oc}}=0.90 \mathrm{~V}$ and $\mathrm{FF}=74.1 \% \quad$ (Fig. 3d; Table 1). The results were highly reproducible. The same PCE of $9.3 \%$ with a $J_{s c}$ of $13.40 \mathrm{~mA} \mathrm{~cm}^{-2}$, a $V_{\text {oc }}$ of $0.90 \mathrm{~V}$ and an extremely high FF of $77.0 \%$ was achieved in Australia (Table 1). This result demonstrates molecular OPVs can achieve comparable efficiencies attainable by polymer-based $\mathrm{OPVs}^{8-11}$. It is worth noting that the FF of $77.0 \%$ is among the highest $\mathrm{FF}$ value reported in the literature for solution-processed molecular $\mathrm{OPVs}^{12,42}$. The average photovoltaic parameters for the 28 devices were $J_{\mathrm{sc}}=13.49 \pm 0.28 \mathrm{~mA} \mathrm{~cm}^{-2}, \quad V_{\mathrm{oc}}=0.89 \pm 0.01 \mathrm{~V}$, $\mathrm{FF}=74 \pm 1 \%$ and $\mathrm{PCE}=8.9 \pm 0.2 \%$ (Table 1$)$.

OPVs of a thick active layer. The high FF values suggest that the BTR-based OPVs can accommodate a greater range of active layer thicknesses. This is particularly important in roll-to-roll printing of very thin films, which are difficult to be precisely controlled, and pinholes are often found in thin-film devices. We were motivated to explore the thickness-dependent solar cell performance using the BTR molecule. Active layers with different thicknesses ranging from 80 to $400 \mathrm{~nm}$ were fabricated by tuning the solution concentrations and spin rates. Figure 4 and Supplementary Table 2 show that BTR-based OPVs maintain a nearly constant $V_{\mathrm{oc}}$ between 0.87 and $0.90 \mathrm{~V}$. The average $J_{\mathrm{sc}}$ increases from $\sim 10$ to $\sim 13 \mathrm{~mA} \mathrm{~cm}^{-2}$ as the active layer thickness increases from 80 to $250 \mathrm{~nm}$ and then it saturates around $13 \mathrm{~mA} \mathrm{~cm}^{-2}$ when the thickness further increases to $400 \mathrm{~nm}$. Surprisingly, the FF values for BTR-based OPVs remain high and close to $70 \%$ even at

Table 1 | Photovoltaic parameters of BTR:PC ${ }_{71}$ BM BHJ solar cells fabricated and tested under different conditions

\begin{tabular}{|c|c|c|c|c|c|c|c|}
\hline$\underline{J s c}_{s A c m}(m)$ & $V_{\text {oc }}(V)$ & FF (\%) & PCE (\%) & $R_{\mathrm{s}}{ }^{\star}\left(\Omega \mathrm{cm}^{2}\right)$ & $R_{\mathrm{sh}}^{\dagger}\left(M \Omega \mathrm{cm}^{2}\right)$ & $\mu_{h}^{\ddagger}\left(\mathrm{cm}^{2} v^{-1} s^{-1}\right)$ & $\mu_{\mathrm{e}^{\ddagger}}^{\ddagger}\left(\mathrm{cm}^{2} \mathrm{v}^{-1} \mathrm{~s}^{-1}\right)$ \\
\hline \multicolumn{8}{|l|}{ As-cast ${ }^{\S}$} \\
\hline 11.64 & 0.96 & 47 & 5.2 & 14.0 & 5.5 & $2.2 \times 10^{-4}$ & $3.5 \times 10^{-4}$ \\
\hline$(11.20 \pm 0.51)$ & $(0.96 \pm 0.01)$ & $(42 \pm 3)$ & $(4.5 \pm 0.4)$ & - & - & & \\
\hline \multicolumn{8}{|l|}{ THF SVA ${ }^{\S}$} \\
\hline 13.52 & 0.89 & 73 & 8.7 & 2.4 & 42 & & \\
\hline [12.16] & {$[0.90]$} & [76] & [8.3] & 2.2 & 6.4 & & \\
\hline \multicolumn{8}{|l|}{ THF SVAll } \\
\hline 13.90 & 0.90 & 74 & 9.3 & 2.7 & 15 & & \\
\hline$[13.40]$ & {$[0.90]$} & {$[77]$} & [9.3] & 1.9 & 20 & & \\
\hline$(13.61 \pm 0.16)$ & $(0.89 \pm 0.01)$ & $(74 \pm 1)$ & $(8.9 \pm 0.2)$ & - & - & & \\
\hline
\end{tabular}

FF, fill factor; PCE, power conversion efficiency; SCLC, space-charge-limited current; SVA, solvent vapour annealing; THF, tetrahydrofuran.

Data in brackets show the cell with the highest FF. Data in parentheses are average results out of $40+$ encapsulated devices tested in air or 28 non-encapsulated devices tested in nitrogen.

Data in brackets show the cell with

$\dagger$ Shunt resistance of the device.

$\ddagger$ Charge mobility values obtained from SCLC experiments.

\$Cells were tested in air with encapsulation, illumination intensity was $98 \mathrm{~mW} \mathrm{~cm}^{-2}$

\|Cells without encapsulation were tested in a glove box filled with dry nitrogen; illumination intensity was $100 \mathrm{~mW} \mathrm{~cm}^{-2}$. 

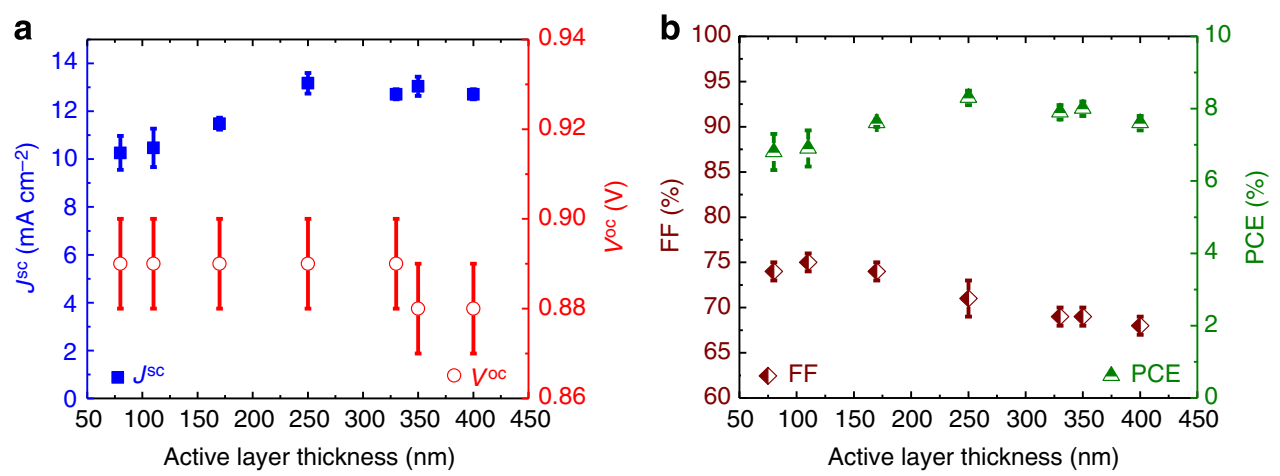

Figure 4 | Active layer thickness-dependent variation of photovoltaic performances. (a) Plots of $J_{\mathrm{sc}}$ or $V_{\mathrm{oc}}$ vs active layer thickness ranging from 80 to $400 \mathrm{~nm}$. (b) Plots of FF or PCE against active layer thickness. The results are an average value of $>8$ devices. The error bars represent the standard deviation from $>8$ devices.
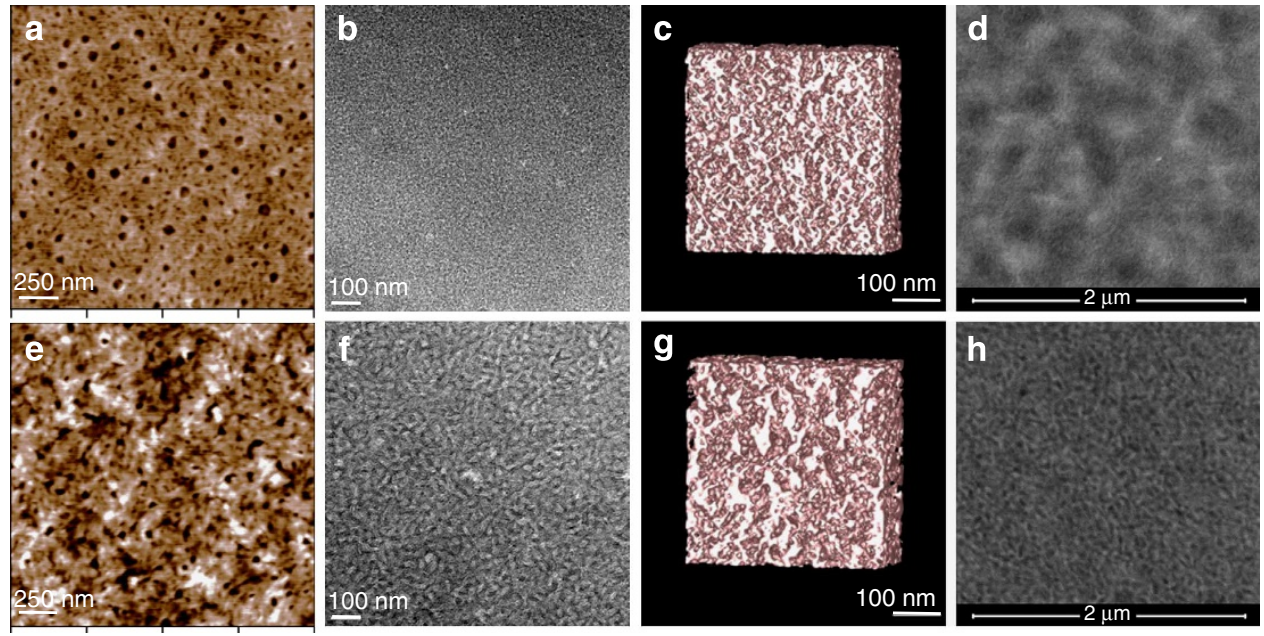

Figure 5 | Solvent vapor annealing induced morphological changes. (a) AFM image shows the topography of an as-cast BTR:PC 71 BM (1:1 weight ratio) blend film. (b) TEM bright-field image of the as-cast film taken at a defocusing range of $3 \mu \mathrm{m}$. (c) Computer model generated from the TEM tomogram of the as-cast film. (d) Low-energy HAADF STEM image of the as-cast film at focus using a beam energy of $15 \mathrm{keV}$. (e) AFM image of the BTR:PC ${ }_{71} B M$ blend film after THF SVA for $15 \mathrm{~s}$. (f) TEM bright-field image of the SVA-treated film at a defocusing range of $3 \mu \mathrm{m}$. (g) Computer model of the THF SVA film. (h) HAADF STEM image of the blend film after SVA treatment.

thicknesses up to $400 \mathrm{~nm}$. This is not commonly observed in thickfilm OPVs, whether it is a molecular OPV or a polymer-based solar cell ${ }^{26-29,43}$. As a result, the overall PCEs formed a flat bell curve with a minimum average value of $6.8 \%$ and maximum average value of $8.3 \%$ at an active layer thickness of $250 \mathrm{~nm}$. The large tolerance for the active layer thickness makes the BTR molecule a strong candidate for printed OPVs.

Solvent vapour annealing. To understand the effect of SVA treatment on the photovoltaic performance of BTR-based OPVs, we carried out studies on active layer morphology and the optoelectronic properties. The surface topography of the active layer was recorded by atomic force microscopy (AFM) operated in the tapping mode. Before the SVA treatment, Fig. 5a depicts a rather smooth surface, with root-mean-square roughness $\left(R_{\mathrm{rms}}\right)$ of $0.61 \mathrm{~nm}$. Fine crystal domains co-exist with random pinholes, which are believed to be related with the escaping of processing solvent. After a short THF SVA treatment of $15 \mathrm{~s}$, the active layer exhibits a coarser surface (Fig. 5e). The $R_{\mathrm{rms}}$ value almost doubles to $1.04 \mathrm{~nm}$. Transmission electron microscopy (TEM) is able to provide morphological information inside the active layer. The brightfield TEM images (Fig. 5b,f) suggest THF SVA treatment leads to larger and more well-defined domains. Because of the sharp contrast in the TEM images, we were able to obtain TEM tomograms and computer models to view the morphological change in 3D (Fig. 5c,g; Supplementary Movies). Both the TEM tomograms and their computer models show that fine-sized domains in the as-cast active layer (Supplementary Movies 1 and 2) evolve into larger domains that are inter-connected to form networks throughout the entire active layer after THF SVA for $15 \mathrm{~s}$ (Supplementary Movies 3 and 4). Such networks resemble '3D charge highways' that are beneficial to fast charge transport. The feature size on TEM images is verified by low-energy high-angle angular dark-field scanning TEM (HAADF STEM) images (Fig. 5d,h).

The SVA treatment can be monitored by colour change of the active layer. The inset of Supplementary Fig. 13 is a digital image of the active layer before and after the THF SVA treatment. The colour of the film changed from maroon to purple upon annealing by THF vapour. Such a colour change was reflected by the change in absorption profile (Supplementary Fig. 13). There was a slight red-shift of the absorption maximum from 555 to $565 \mathrm{~nm}$. Besides, the shoulder at $620 \mathrm{~nm}$ became more prominent, suggesting good alignment of the rod-like molecules. The absorption enhancement at $620 \mathrm{~nm}$ directly translated to increased photocurrent, as suggested by the EQE plot (Fig. 3c).

GIWAXS measurements were performed to understand the organization of BTR in the active layer before and after SVA. In comparison with the BTR neat film, the edge-on layered 
organization remains unchanged in the as-cast $\mathrm{BTR}: \mathrm{PC}_{71} \mathrm{BM}$ blend film, while the $\pi$-stacking distance slightly increases to $3.80 \AA$ and becomes randomly distributed towards the surface, as confirmed by the isotropic intensity of the corresponding peak (Supplementary Fig. 14a). The amorphous halo at $q$-range of ca. $1.25 \AA^{-1}$ is attributed to $\mathrm{PC}_{71} \mathrm{BM}$ domains. SVA improves the crystallinity and surface ordering of BTR. The interlayer distance is reduced to $17.75 \AA$, while the $\pi$-stacking distance decreases to $3.60 \AA$. The random orientation of $\pi$-stacking evolves into the coexistence of both edge-on and face-on arrangements after SVA, evidenced from the $\pi$-stacking reflections at $c a$. $1.7 \AA^{-1}$ in both $q_{\mathrm{xy}}$ and $q_{\mathrm{z}}$ directions (Supplementary Fig. 14b). Such a molecular arrangement is beneficial to $3 \mathrm{D}$ charge transport.

SCLC mobilities. The hole mobility was measured using the SCLC method with a cell architecture: ITO/PEDOT:PSS/ BTR:PC ${ }_{71} \mathrm{BM} / \mathrm{Au}$. Without SVA treatment, the blend film exhibited a relatively high hole mobility of $2.2 \times 10^{-4} \mathrm{~cm}^{2}$ $\mathrm{V}^{-1} \mathrm{~s}^{-1}$ (Supplementary Fig. 15; Table 1). The rigid and planar backbone facilitates easy stacking and strong intermolecular interaction due to side-chain modifications. The SVA treatment substantially enhanced the mobility by one order of magnitude to $1.6 \times 10^{-3} \mathrm{~cm}^{2} \mathrm{~V}^{-1} \mathrm{~s}^{-1}$, which is comparable to or greater than those reported for high-performing donor:acceptor blend systems $7,31,41,44,45$. The electron mobility derived from the SCLC method was also improved by one order of magnitude after SVA treatment (Supplementary Fig. 16; Table 1). Such an enhancement can be attributed to larger and more structured domains, as well as better molecular arrangement. The extremely high mobility would partially account for the high FF observed in BTR-based OPVs. However, we do not exclude other possible factors including vertical phase separation or removal of recombination centres and so on $^{33}$.

Solar cell stability. For practical application, solar cell-stability experiments were carried out in both air and nitrogen environments. Due to the use of active metal-like calcium for the top electrode, the unencapsulated OPVs of the thick active layer ( $\sim 400 \mathrm{~nm}$ ) degraded to almost zero efficiency within three days of storage in air (Supplementary Fig. 17; Supplementary Table 3). However, a simple encapsulation with ultraviolet (UV)-curable epoxy and thin glass slides could greatly improve the device stability in air. The OPVs degraded three times slower than that without encapsulation (Supplementary Fig. 17; Supplementary Table 4). To minimize the degradation factor due to the oxidation of electrode and further explore the stability of the active layer, one BTR-based solar cell device was stored in a glove box filled with dry nitrogen and was monitored over a time span of 30 days. The cell retained $86 \%$ of initial PCE after 7 days, and it exhibited $>50 \%$ of original PCE after 30 days of storage (Supplementary Fig. 18a,b; Supplementary Table 5). Further enhancement of device stability could be achieved by improved device architecture. Average of $10 \mathrm{OPV}$ cells of thick active layer of $400 \mathrm{~nm}$ and an additional 30-nm-thick silver top electrode/protection layer with or without encapsulation retained 92 and $86 \%$ of initial average PCE after 30 days of storage in a glove box (Supplementary Fig. 18c; Supplementary Tables 6 and 7). We believe even better stability can be obtained if the cells were properly encapsulated or inverted cell architecture was employed.

\section{Discussion}

In summary, we present a new molecular donor, BTR, which possesses a rigid and flat backbone and a large number of flexible side chains that could work synergistically to provide excellent processability, nematic liquid crystal behaviour and optoelectronic properties. The neat BTR film exhibited hole mobilities up to $0.1 \mathrm{~cm}^{2} \mathrm{~V}^{-1} \mathrm{~s}^{-1}$ in OFET devices. The solutionprocessed single-junction BHJ solar cells based on BTR and $\mathrm{PC}_{71} \mathrm{BM}$ demonstrated a reproducible record efficiency of $9.3 \%$. The blend film also supported a high FF of $77 \%$ and a high SCLC hole mobility of $1.6 \times 10^{-3} \mathrm{~cm}^{2} \mathrm{~V}^{-1} \mathrm{~s}^{-1}$ after SVA with THF. Thick-film molecular solar cells with an active layer thickness up to $400 \mathrm{~nm}$ were demonstrated, showing a low thickness dependence of photovoltaic performance. Together, the results suggest BTR is an ideal candidate for printed OPVs. Moreover, enhancing the intermolecular interaction through side-chain modification is a viable way further to enhance the efficiency of molecular solar cells in excess of $10 \%$.

\section{Methods}

Materials. Unless noted, all materials were reagent grade and used as received without further purification. Anhydrous solvents were prepared by drying HPLC-grade solvents using freshly activated molecular sieves.

Synthesis of aldehyde compound 3. Synthetic route could be found in Supplementary Fig. 1. Precursor $\mathbf{1}$ and $\mathbf{2}$ were prepared using literature methods ${ }^{46,47}$. In protection of $\mathrm{N}_{2}$, to a dry $250-\mathrm{ml}$ flask were added compound $\mathbf{1}$ $(1.07 \mathrm{~g}, 1.0 \mathrm{mmol})$, compound $2(1.05 \mathrm{~g}, 2.0 \mathrm{mmol}), \mathrm{Pd}_{2}(\mathrm{dba})_{3}(46 \mathrm{mg}, 0.04 \mathrm{mmol})$, $\mathrm{P}(o \text {-tolyl })_{3}(97 \mathrm{mg}, 0.32 \mathrm{mmol})$ and $50 \mathrm{ml}$ of toluene. The reaction mixture was refluxed at $125^{\circ} \mathrm{C}$ for $12 \mathrm{~h}$. The reaction mixture was filtered and the crude product was purified by silica gel column chromatography (petroleum spirit $40-60^{\circ} \mathrm{C}$ : dichloromethane $\left.=1: 1.5, R_{\mathrm{f}} 0.5\right)$ to give the product as yellow solid ( $830 \mathrm{mg}, 53 \%$ ). $\mathrm{mp} 146-147^{\circ} \mathrm{C}$; infrared (IR) (neat) $\vee 2,955,2,923,2,855,1,656,1,432,1,225,1,058$ 820,786 and $663 \mathrm{~cm}^{-1} ;{ }^{1} \mathrm{H}$ NMR $\left(\delta, \mathrm{CDCl}_{3}\right) 9.89(\mathrm{~s}, 2 \mathrm{H}), 7.72(\mathrm{~d}, J=4.0 \mathrm{~Hz}, 2 \mathrm{H})$, $7.68(\mathrm{~s}, 2 \mathrm{H}), 7.23(\mathrm{~d}, J=4.0 \mathrm{~Hz}, 2 \mathrm{H}), 7.12(\mathrm{~s}, 2 \mathrm{H}), 7.01(\mathrm{~s}, 2 \mathrm{H}), 2.82(\mathrm{~m}, 12 \mathrm{H})$, $2.65(\mathrm{~m}, 4 \mathrm{H}), 1.60-1.75(\mathrm{~m}, 14 \mathrm{H}), 1.26-1.45(\mathrm{~m}, 52 \mathrm{H}), 0.88(\mathrm{~m}, 30 \mathrm{H}) ;{ }^{13} \mathrm{C} \mathrm{NMR}$ $\left(\delta, \mathrm{CDCl}_{3}\right) 182.6,146.1,142.6,142.2,141.2,139.6,139.0,138.6,137.3,137.2,136.9$, $136.0,135.8,134.8,130.3,129.8,129.5,129.1,128.3,125.9,123.5,119.5,41.7,32.7$, $32.3,31.8,31.6,30.8,30.4,30.2,29.8,29.6,29.3,29.2,29.1,28.9,28.4,26.0,23.1$, 22.7, 22.6, 14.2 and 13.1; mass spectrometry (MS) (matrix-assisted laser desorption/ionization (MALDI)) $m / z$ 1,630 [M].

Synthesis of BTR molecule. To the solution of compound 3 ( $327 \mathrm{mg}, 0.2 \mathrm{mmol}$ ) in dry chloroform $(20 \mathrm{ml})$ was added rhodanine $4(434 \mathrm{mg}, 2.0 \mathrm{mmol})$ followed by one drop of 1,8-Diazabicyclo[5.4.0] undec-7-ene (DBU). The reaction mixture was then placed under continuous stirring at room temperature for $3 \mathrm{~h}$. Reaction solvent was removed and the crude product was purified by silica gel column chromatography (petroleum spirit $40-60^{\circ} \mathrm{C}$ : dichloromethane $=1: 1, R_{\mathrm{f}} 0.8$ ). The desired fractions were collected and the product was obtained as a purple solid $(310 \mathrm{mg}, 76 \%)$ after washing with acetone. $\mathrm{mp} 178-180^{\circ} \mathrm{C}$; IR (neat) $v 2,924,2,855,1,699,1,575,1,423$, 1,327, 1,238, 1,180 and $820 \mathrm{~cm}^{-1}$; ${ }^{1} \mathrm{H} \operatorname{NMR}\left(\delta, \mathrm{CDCl}_{3}\right) 7.83(\mathrm{~s}, 2 \mathrm{H}), 7.65(\mathrm{~s}, 2 \mathrm{H})$, $7.35(\mathrm{~d}, J=4.0 \mathrm{~Hz}, 2 \mathrm{H}), 7.23(\mathrm{~s}, 2 \mathrm{H}), 7.20(\mathrm{~d}, J=4.0 \mathrm{~Hz}, 2 \mathrm{H}), 7.10(\mathrm{~s}, 2 \mathrm{H}), 7.00(\mathrm{~s}$, $2 \mathrm{H}), 4.09(\mathrm{t}, J=7.6 \mathrm{~Hz}, 4 \mathrm{H}), 2.81(\mathrm{~m}, 12 \mathrm{H}), 2.78(\mathrm{~m}, 4 \mathrm{H}), 1.60-1.75(\mathrm{~m}, 18 \mathrm{H})$, $1.26-1.45(\mathrm{~m}, 64 \mathrm{H}), 0.88(\mathrm{~m}, 36 \mathrm{H}) ;{ }^{13} \mathrm{C} \mathrm{NMR}\left(\delta, \mathrm{CDCl}_{3}\right) 192.2,167.5,144.3,141.9$, $141.0,139.5,139.0,138.6,137.3,137.2,137.1,135.7,135.6,134.8,134.6,130.4,129.8$, $129.7,129.0,128.3,126.5,125.0,123.5,120.2,119.5,44.9,41.7,32.7,32.4,31.8,31.7$ $31.6,31,3,30.8,30.4,30.3,29.8,29.7,29.3,29.2,29.1,28.9,28.4,27.0,26.4,26.0,23.1$, 22.7, 22.6, 22.5, 14.2, 13.1; MS (MALDI) $\mathrm{m} / z$ 2,028.7 [M] ${ }^{+}$. Elemental analyses calcd (\%) for $\mathrm{C} 114 \mathrm{H} 152 \mathrm{~N} 2 \mathrm{O} 2 \mathrm{~S} 14$ (BTR): C, 67.41; H, 7.54; N, 1.38; O, 1.58; S, 22.10; found: C, $67.64 ; \mathrm{H}, 7.65 ; \mathrm{N}, 1.24 ; \mathrm{O}, 1.33 ; \mathrm{S}, 21.87$.

Material characterizations. IR spectra were obtained on a Perkin-Elmer Spectrum One Fourier transform infrared spectrometer and UV-visible spectra were recorded using a Cary $50 \mathrm{UV}$-visible spectrometer. Photoluminescence was measured with a Varian Cary Eclipse fluorimeter. Melting points were determined on a Büchi 510 melting point apparatus. ${ }^{1} \mathrm{H}$ NMR and ${ }^{13} \mathrm{C}$ NMR spectra were carried out on a $400-\mathrm{MHz}$ spectrometer. All NMR data were referenced to the chloroform signal and peak multiplicity was reported as follows: $s=$ singlet, $\mathrm{d}=$ doublet, $\mathrm{t}=$ triplet, $\mathrm{q}=$ quartet, $\mathrm{p}=$ pentet, $\mathrm{dd}=$ doublets of doublets, $\mathrm{m}=$ multiplet and $\mathrm{br}=$ broad). MALDI-time-of-flight MS was performed on a Bruker microflex instrument, using chloroform as solvent and dithranol as the assisted matrix. Elemental analyses were obtained commercially through Chemical \& Analytical Services Pty Ltd. (Australia) an Exeter Analytical CE-440 elemental analyzer. Thermal gravimetric analysis experiments were carried out with a Mettler Toledo TGA/SDTA851e, and DSC experiments were performed on a Perkin-Elmer Sapphire DSC. CV experiments were performed at a sweep rate of $100 \mathrm{mV} \mathrm{s}^{-1}$. CVs were carried out in a three-electrode cell consisting of a glassy carbon working electrode, a platinum wire auxiliary electrode and a $\mathrm{Ag} / \mathrm{Ag}^{+}$pseudo-reference electrode. The supporting electrolyte was $0.10 \mathrm{M}$ tetrabutylammonium hexafluorophosphate $\left(\mathrm{Bu}_{4} \mathrm{NPF}_{6}\right)$ in $\mathrm{CH}_{3} \mathrm{CN}$. The solutions were deoxygenated by sparging with argon prior to each scan and blanketed with argon during the scans. 
The glassy carbon working electrode was prepared by polishing with $5 \mathrm{~mm}$ alumina and washed and dried before the polymer was drop-casted on the electrode from chlorobenzene solution to form a film. Ferrocene/ferrocenium redox couple was used as the internal standard. The HOMO energy level was calculated from the onset of the oxidation potential of the polymer using the following: $E_{\mathrm{HOMO}}=-\left(4.8+E_{\mathrm{ox}}\right.$ onset $) \mathrm{eV}$.

Crystal structure determination. Single-crystal data were collected on the MX2 beamline at The Australian Synchrotron at $100 \mathrm{~K}$ using a $360^{\circ}$ rotation in steps of $1^{\circ}$ with 1-s exposure time per step. The beamline was set to the Mo-K- $\alpha$ edge (17.444 keV or $0.71073 \AA$ ). Crystal data for BTR: C112 H150 N2 O2 S14, $M=2,005.17, T=100.0(2) \mathrm{K}, \lambda=0.71073 \AA$, Triclinic, space group $P$ - 1 , $a=314.257(3), b=20.519(4), c=21.795(4) \AA, \alpha=114.76(3)^{\circ}, \beta=98.08(3)^{\circ}$ $\gamma=02.00(3)^{\circ}, V=5,474(2) \AA^{3}, Z=2, D_{\mathrm{c}}=1.217 \mathrm{Mg} \mathrm{M}^{-3}, \mu=0.326 \mathrm{~mm}^{-1}$ $F(000)=2,152$, crystal size $0.10 \times 0.05 \times 0.05 \mathrm{~mm} . \theta_{\max }=27.47^{\circ}, 88,775$ reflections measured, 22,889 independent reflections $\left(R_{\mathrm{int}}=0.055\right)$ the final $R=0.11$ $\left(I>2 \sigma(I), 14,445\right.$ data) and $w R\left(F^{2}\right)=0.3696$ (all data) GOOF $=1.371$.

Thin-film characterizations. To study the liquid crystal property of BTR, we used a Nikon Eclipse LV100 POM equipped with Linkam LTS350 heating and cooling stage connected to a Linkam TMS 94 temperature programmer. GIWAXS samples were prepared by spin-coating chloroform solution of BTR onto PEDOT:PSScoated silicon substrates. The measurements were performed by means of a solid anode X-ray tube (Siemens Kristalloflex X-ray source, copper anode X-ray tube operated at $35 \mathrm{kV}$ and $40 \mathrm{~mA}$ ), Osmic confocal MaxFlux optics, X-ray beam with pinhole collimation and a MAR345 image plate detector. The beam size was $0.5 \times 0.5 \mathrm{~mm}$ and samples were irradiated just below the critical angle for total reflection with respect to the incoming X-ray beam $\left(\sim 0.18^{\circ}\right)$. The scattering intensity was detected on a 2D image plate (MAR345) with a pixel size of $100 \mu \mathrm{m}$ $(3,450 \times 3,450$ pixels $)$. Data analysis was performed using the Datasqueeze 3.0.0 software. Atomic force microscopy images were acquired using an Asylum Research Cypher scanning probe microscope operated in tapping mode. Samples for electron microscopy were prepared by dissolving the PEDOT:PSS layer using water and transferring the floating active layer to TEM grids. TEM bright-field images were obtained by a FEI Tecnai TF30 TEM equipped a with beam-blank function. For TEM tomography, tilt series were acquired using the Xplore 3D software (FEI Company). Tomograms were recorded between -65 and +65 degrees at $2^{\circ}$ intervals and aligned with IMOD. A 3D model rendering employed $3 \mathrm{~d}$ mod software. Each model was generated from the aligned tomogram. The BTR donor phase was rendered in pink colour, while the $\mathrm{PC}_{71} \mathrm{BM}$ acceptor phase was represented by empty space in model movies. The scale bar was $100 \mathrm{~nm}$ in both the model movies and the tomogram movies. HAADF STEM was performed at a primary electron energy of $15 \mathrm{keV}$ with a FEI Quanta 3D Microscope equipped with a HAADF STEM detector. To obtain hole and electron mobilities using SCLCs, hole-only devices (ITO/PEDOT:PSS/BTR:PC ${ }_{71} \mathrm{BM} / \mathrm{Au}$ ) and electron-only devices (ITO/Al/ BTR:PC ${ }_{71} \mathrm{BM} / \mathrm{Al}$ ) were constructed. Their dark currents were recorded by a computer-programmed Keithley 2400 source meter and then fitted by the Mott-Gurney equation. Film thickness was determined by a Veeco Dektak $150+$ Surface Profiler.

Solvent vapour annealing. SVA was conducted in a glove box filled with dried nitrogen. THF $(1 \mathrm{ml})$ were injected into a $30-\mathrm{mm}$ glass Petri dish. The Petri dish was closed for $1 \mathrm{~min}$ to let the vapour saturate the treatment chamber. Then as-cast films were attached on the backside of the Petri dish lid, which was quickly swapped with the lid covering the solvent-containing Petri dish. The film was about $1 \mathrm{~cm}$ above the solvent level during the SVA. After certain duration, the film was removed from the treatment chamber. The optimal duration in this study was $15 \mathrm{~s}$.

OFET fabrication and measurement. OFETs were fabricated employing two types of device configurations: bottom-gate, bottom-contact and bottom-gate, top-contact on the $300-\mathrm{nm}$-thick silicon-dioxide dielectric covering the highly doped silicon that acted as the gate electrode. The source-drain channel length $(L)$ to channel width $(W)$ ratio was 1:70 for bottom-contact and 1:33 for top-contact configurations. The substrates were first cleaned by sonication in acetone and isopropanol for $20 \mathrm{~min}$ each, then dried under nitrogen flow and dipped into a freshly prepared piranha solution $\left(7: 3 \mathrm{v} / \mathrm{v} \mathrm{H}_{2} \mathrm{SO}_{4} / 30 \% \mathrm{H}_{2} \mathrm{O}_{2}\right)$ at $90^{\circ} \mathrm{C}$ for $60 \mathrm{~min}$. To remove residues of the piranha solution, substrates were rinsed with copious deionized water and dried under nitrogen flow. The BTR thin film was deposited via spin-coating (for top-contact OFETs) or drop-casting (bottom-contact OFETs) using $4.5 \mathrm{mg} \mathrm{ml}^{-1}$ toluene with subsequent annealing at $60^{\circ} \mathrm{C}$ for $60 \mathrm{~min}$ to remove residual solvent. In addition, the BTR films were measured after thermal annealing at 179 and $190^{\circ} \mathrm{C}$. All the electrical measurements are performed in a glove box under nitrogen atmosphere by means of a Keithley 4200 SCS.

Solar cell fabrication and characterization. Patterned ITO glasses were washed sequentially by detergent, deionized water, acetone and 2-propanol in an ultrasonication bath and UV/ozone-treated. PEDOT:PSS (Clevios P VP AI 4083) was spin-coated at 6.000 r.p.m. and then baked at $140^{\circ} \mathrm{C}$ for $10 \mathrm{~min}$ in air. The substrates were transferred to a glove box filled with dried nitrogen, where a chloroform solution of the donor-acceptor blend was spin coated at various spin rates on top of the substrate. The best PCE was achieved by spin coating $20 \mathrm{mg}$ BTR and $20 \mathrm{mg} \mathrm{PC}_{71} \mathrm{BM}$ in $1 \mathrm{ml}$ of chloroform at 1,000 r.p.m. The resulting film thickness was around $250 \mathrm{~nm}$. Thicker or thinner films were produced by varying the solution concentration and spin rate from 1.6 to $2.0 \%$ and from 600 to 2,000 r.p.m., respectively. To obtain high photovoltaic performance, the films were solvent vapour annealed by THF. Then they were transferred to a thermal evaporator where $40 \mathrm{~nm} \mathrm{Ca}$ and $100 \mathrm{~nm}$ aluminium were deposited through a shadow mask (active area was $0.11 \mathrm{~cm}^{2}$ ) at a base pressure of $4 \times 10^{-7} \mathrm{mbar}$. The solar cells were encapsulated under nitrogen by UV-curable epoxy (Epotek OG112-6 by Epoxy Technology Inc.) and cover glass. They were tested in air with a computerprogrammed Keithley 2400 source meter under a Newport Oriel class A solar similar, which simulated the AM1.5 solar irradiance with energy density of $98 \mathrm{~mW} \mathrm{~cm}^{-2}$. For accurate measurement and to avoid oxidation during testing, a batch of optimized solar cells were brought to a third-party research institute, Solar Energy Research Institute of Singapore, where the cells were tested under nitrogen and 1 SUN $\left(100 \mathrm{~mW} \mathrm{~cm}^{-2}\right)$ condition provided by a $1 \mathrm{~kW}$ solar simulator (Sun 2000 Solar Simulator by ABET Technologies) that was calibrated by a silicon reference cell (Fraunhofer ISE) and a Schott visible-colour glass-filtered (KG5 colour filtered) Si diode (Hamamatsu S1133). OPVs made in Australia followed the same fabrication procedures, and were tested at Clayton Laboratories of Commonwealth Scientific and Industrial Research Organisation, where a 1-kW Oriel solar simulator with an AM 1.5G filter was used as the light source.

\section{References}

1. Burschka, J. et al. Sequential deposition as a route to high-performance perovskite-sensitized solar cells. Nature 499, 316-319 (2013).

2. Liu, M., Johnston, M. B. \& Snaith, H. J. Efficient planar heterojunction perovskite solar cells by vapour deposition. Nature 501, 395-398 (2013).

3. Zhou, H. et al. Interface engineering of highly efficient perovskite solar cells. Science 345, 542-546 (2014).

4. Yu, G., Gao, J., Hummelen, J. C., Wudl, F. \& Heeger, A. J. Polymer photovoltaic cells: enhanced efficiencies via a network of internal donor-acceptor heterojunctions. Science 270, 1789-1791 (1995).

5. Chen, H. Y. et al. Polymer solar cells with enhanced open-circuit voltage and efficiency. Nat. Photon. 3, 649-653 (2009).

6. Small, C. E. et al. High-efficiency inverted dithienogermolethienopyrrolodione-based polymer solar cells. Nat. Photon. 6, 115-120 (2012).

7. Liu, Y. et al. Solution-processed small-molecule solar cells: breaking the $10 \%$ power conversion efficiency. Sci. Rep. 3, 3356 (2013).

8. He, Z. et al. Enhanced power-conversion efficiency in polymer solar cells using an inverted device structure. Nat. Photon. 6, 591-595 (2012).

9. Ye, L., Zhang, S., Zhao, W., Yao, H. \& Hou, J. Highly efficient 2D-conjugated benzodithiophene-based photovoltaic polymer with linear alkylthio side chain. Chem. Mater. 26, 3603-3605 (2014).

10. Liao, S.-H., Jhuo, H.-J., Cheng, Y.-S. \& Chen, S.-A. Fullerene derivative-doped zinc oxide nanofilm as the cathode of inverted polymer solar cells with lowbandgap polymer (PTB7-Th) for high performance. Adv. Mater. 25, 4766-4771 (2013).

11. Guo, X. et al. Enhanced photovoltaic performance by modulating surface composition in bulk heterojunction polymer solar cells based on PBDTTT-CT/PC ${ }_{71}$ BM. Adv. Mater. 26, 4043-4049 (2014).

12. Gupta, V. et al. Barium: an efficient cathode layer for bulk-heterojunction solar cells. Sci. Rep. 3, 1965 (2013).

13. Li, C.-Z. et al. Suppressed charge recombination in inverted organic photovoltaics via enhanced charge extraction by using a conductive fullerene electron transport layer. Adv. Mater. 26, 6262-6267 (2014).

14. Walker, B., Kim, C. \& Nguyen, T.-Q. Small molecule solution-processed bulk heterojunction solar cells. Chem. Mater. 23, 470-482 (2010).

15. Mishra, A. \& Bäuerle, P. Small molecule organic semiconductors on the move: promises for future solar energy technology. Angew. Chem. Int. Ed. 51, 2020-2067 (2012).

16. Lin, Y., Li, Y. \& Zhan, X. Small molecule semiconductors for high-efficiency organic photovoltaics. Chem. Soc. Rev. 41, 4245-4272 (2012).

17. Shin, W., Yasuda, T., Watanabe, G., Yang, Y. S. \& Adachi, C. Self-organizing mesomorphic diketopyrrolopyrrole derivatives for efficient solution-processed organic solar cells. Chem. Mater. 25, 2549-2556 (2013).

18. Graham, K. R. et al. Improved performance of molecular bulk-heterojunction photovoltaic cells through predictable selection of solvent additives. Adv. Funct. Mater. 22, 4801-4813 (2012).

19. Wang, H. et al. The role of additive in diketopyrrolopyrrole-based small molecular bulk heterojunction solar cells. Adv. Mater. 25, 6519-6525 (2013).

20. Graham, K. R. et al. Tailor-made additives for morphology control in molecular bulk-heterojunction photovoltaics. ACS Appl. Mater. Interfaces 5, 63-71 (2013).

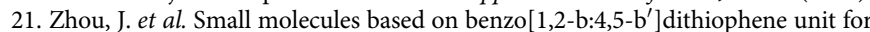
high-performance solution-processed organic solar cells. J. Am. Chem. Soc. 134, 16345-16351 (2012). 
22. Wei, G., Wang, S., Sun, K., Thompson, M. E. \& Forrest, S. R. Solvent-annealed crystalline squaraine: $\mathrm{PC}_{70} \mathrm{BM}(1: 6)$ solar cells. Adv. Energy Mater. 1, 184-187 (2011).

23. Sun, K. et al. The role of solvent vapor annealing in highly efficient airprocessed small molecule solar cells. J. Mater. Chem. A 2, 9048-9054 (2014).

24. Wessendorf, C. D. et al. Efficiency improvement of solution-processed dithienopyrrole-based A-D-A oligothiophene bulk-heterojunction solar cells by solvent vapor annealing. Adv. Energy Mater. 4, 1400266 (2014).

25. Krebs, F. C. Fabrication and processing of polymer solar cells: a review of printing and coating techniques. Sol. Energy Mater. Sol. Cells 93, 394-412 (2009).

26. Li, W. et al. Efficient small bandgap polymer solar cells with high fill factors for $300 \mathrm{~nm}$ thick films. Adv. Mater. 25, 3182-3186 (2013).

27. Li, G., Shrotriya, V., Yao, Y. \& Yang, Y. Investigation of annealing effects and film thickness dependence of polymer solar cells based on poly(3-hexylthiophene). J. Appl. Phys. 98, 043704 (2005).

28. Murphy, L., Hong, W., Aziz, H. \& Li, Y. Organic photovoltaics with thick active layers $(\sim 800 \mathrm{~nm})$ using a high mobility polymer donor. Sol. Energy Mater. Sol. Cells 114, 71-81 (2013).

29. Zeng, L., Tang, C. W. \& Chen, S. H. Effects of active layer thickness and thermal annealing on polythiophene: fullerene bulk heterojunction photovoltaic devices. Appl. Phys. Lett. 97, 053305 (2010).

30. Wang, N., Chen, Z., Wei, W. \& Jiang, Z. Fluorinated benzothiadiazole-based conjugated polymers for high-performance polymer solar cells without any processing additives or post-treatments. J. Am. Chem. Soc. 135, 17060-17068 (2013).

31. Zhou, J. et al. Solution-processed and high-performance organic solar cells using small molecules with a benzodithiophene unit. J. Am. Chem. Soc. 135, 8484-8487 (2013).

32. Kline, R. J. et al. Critical role of side-chain attachment density on the order and device performance of polythiophenes. Macromolecules 40, 7960-7965 (2007).

33. Kim, M. S., Kim, B. G. \& Kim, J. Effective variables to control the fill factor of organic photovoltaic cells. ACS Appl. Mater. Interfaces 1, 1264-1269 (2009).

34. Bredas, J. L., Norton, J. E., Cornil, J. \& Coropceanu, V. Molecular understanding of organic solar cells: the challenges. Acc. Chem. Res. 42, 1691-1699 (2009).

35. Schmidt-Mende, L. et al. Self-organized discotic liquid crystals for highefficiency organic photovoltaics. Science 293, 1119-1122 (2001).

36. Goel, M. \& Jayakannan, M. Supramolecular liquid crystalline $\pi$-conjugates: the role of aromatic $\pi$-stacking and van der Waals forces on the molecular self-assembly of oligophenylenevinylenes. J. Phys. Chem. B 114, 12508-12519 (2010).

37. Kim, B.-G. et al. A molecular design principle of lyotropic liquid-crystalline conjugated polymers with directed alignment capability for plastic electronics. Nat. Mater. 12, 659-664 (2013).

38. Hanna, J.-i., Ohno, A. \& Iino, H. Charge carrier transport in liquid crystals. Thin Solid Films 554, 58-63 (2014).

39. McPhillips, T. M. et al. Blu-Ice and the distributed control system: software for data acquisition and instrument control at macromolecular crystallography beamlines. J. Synchrotron Radiat. 9, 401-406 (2002).

40. Guo, X., Puniredd, S. R., Baumgarten, M., Pisula, W. \& Müllen, K Benzotrithiophene-based donor-acceptor copolymers with distinct supramolecular organizations. J. Am. Chem. Soc. 134, 8404-8407 (2012).

41. Guo, X. et al. Polymer solar cells with enhanced fill factors. Nat. Photon. 7, 825-833 (2013)

42. Lin, Y. et al. Small-molecule solar cells with fill factors up to 0.75 via a layer-by-layer solution process. Adv. Energy Mater. 4, 1300626 (2014).

43. Murphy, L., Hong, W., Aziz, H. \& Li, Y. Influences of using a high mobility donor polymer on solar cell performance. Org. Electron. 14, 3484-3492 (2013)
44. Liang, Y. et al. For the bright future: bulk heterojunction polymer solar cells with power conversion efficiency of 7.4\%. Adv. Mater. 22, E135-E138 (2010)

45. Kyaw, A. K. K. et al. Intensity dependence of current-voltage characteristics and recombination in high-efficiency solution-processed small-molecule solar cells. ACS Nano 7, 4569-4577 (2013).

46. Qin, T. et al. Tailored donor-acceptor polymers with an A-D1-A-D2 structure: controlling intermolecular interactions to enable enhanced polymer photovoltaic devices. J. Am. Chem. Soc. 136, 6049-6055 (2014).

47. Kumar, R. J., MacDonald, J. M., Singh, T. B., Waddington, L. J. \& Holmes, A. B. Hierarchical self-assembly of semiconductor functionalized peptide $\alpha$-helices and optoelectronic properties. J. Am. Chem. Soc. 133, 8564-8573 (2011).

\section{Acknowledgements}

This research was supported by the Victorian Organic Solar Cell Consortium with funding from the Victorian Government (DSDBI) and the Australian Renewable Energy Agency (ARENA) through grants 2-A018, 1-GER001 and the ARENA funded Australian Centre for Advanced Photovoltaics. The research was also supported by the Ministry of Education, Singapore (R-284-000-113-112). W.W.H.W. is supported by an ARC Future Fellowship (FT130100500). We acknowledge the Monash Centre for Electron Microscopy (MCEM) at Monash University, the MX2 beamline at the Australian Synchrotron, CSIRO, Department of Materials Science \& Engineering (DMSE) at National University of Singapore (NUS) and Solar Energy Research Institute of Singapore (SERIS) for sharing their facilities with us. We acknowledge Dr Doojin Vak at CSIRO, Dr Xi-Ya Fang at MCEM, Henche Kuan, Yeow Koon Liew, Drs Lei Chen and Pengcheng Li at DMSE NUS and Fang Jeng Lim at SERIS for experiment assistance and in-depth discussions.

\section{Author contributions}

K.S. fabricated the solar cell device and characterized the film and device properties using POM, XRD, AFM, TEM, HAADF STEM and SCLC. Z.X. designed and performed materials synthesis and characterization including NMR, MS, CV and UV-vis absorption spectra for solution and thin film. S.L. scaled up the synthesis, grew single crystals and measured DSC, TGA, PL and solubility. W.Z. and W.P. fabricated OFET, measured and analysed OFET, 2D-XRD and GIWAXS data. E.H. constructed TEM tomograms and computer models. J.M.W. solved the crystal structure using XRD acquired by R.M.W. at Australian Synchrotron. J.S. reproduced the OPV results. K.S., Z.X. and S.L. prepared the manuscript. All authors discussed the results and commented on the manuscript. J.O., W.W.H.W., A.B.H. and D.J.J. supervised the project and revised the manuscript.

\section{Additional information}

Accession codes: The crystallographic information file for BTR has been deposited with Cambridge Crystallographic Data Centre, and signed to CCDC code 1029304.

Supplementary Information accompanies this paper at http://www.nature.com/ naturecommunications

Competing financial interests: The authors declare no competing financial interests

Reprints and permission information is available online at http://npg.nature.com/ reprintsandpermissions/

How to cite this article: Sun, K. et al. A molecular nematic liquid crystalline material for high-performance organic photovoltaics. Nat. Commun. 6:6013 doi: 10.1038/ ncomms7013 (2015)

(c) (i) This work is licensed under a Creative Commons Attribution 4.0 International License. The images or other third party material in this article are included in the article's Creative Commons license, unless indicated otherwise in the credit line; if the material is not included under the Creative Commons license, users will need to obtain permission from the license holder to reproduce the material. To view a copy of this license, visit http://creativecommons.org/licenses/by/4.0/ 